\title{
Reversal of diabetic retinopathy by continuous subcutaneous insulin infusion: a case report
}

\author{
M. C. WHITE, ${ }^{1}$ EVA M. KOHNER, ${ }^{1}$ J. C. PICKUP,${ }^{2}$ AND HARRY KEEN, ${ }^{2}$ \\ From the ${ }^{1}$ Department of Medicine, Royal Postgraduate Medical School, Hammersmith Hospital, and the \\ ${ }^{2}$ Unit of Human Metabolism, Guy's Hospital Medical School, London
}

SUMMARY We report the case history of a 20-year-old diabetic girl with long-standing poorly controlled disease who presented with severe retinopathic features and who was treated with continuous subcutaneous insulin infusion (CSII). When first seen she had macular oedema and a visual acuity of $6 / 18$ in her only eye, together with multiple blot haemorrhages and intraretinal microvascular abnormalities. Marked reversal of the retinal lesions occurred within 65 days of initiating CSII and after only 36 days of constant normoglycaemia. Subsequent good blood glucose control on conventional subcutaneous insulin injections has been achieved, and the retinopathy remains quiescent with a visual acuity of $6 / 5$. We suggest that CSII may be a potentially useful method of arresting and reversing early diabetic retinopathy.

Many factors, genetic and environmental, influence the appearance and severity of diabetic retinopathy, but evidence from animal studies strongly suggests that poor diabetic control is important in its initiation and evolution. ${ }^{1}$ In the human diabetic the difficulty of achieving a prolonged near-normal metabolic state with conventional methods of insulin administration has made the role of 'control' in retinopathy difficult to evaluate. The introduction of the new technique of continuous subcutaneous insulin infusion (CSII) with a portable variable-rate battery-operated syringe pump ${ }^{2}$ has provided the means of observing the effects of dramatically improved control on diabetic retinopathy. CSII not only maintains near-normoglycaemia in fully ambulant patients for several months ${ }^{34}$ but also returns the circadian profiles of some major intermediate metabolites towards the nondiabetic state. ${ }^{56}$

We therefore submitted a diabetic girl with severe retinopathy, previously poorly controlled on conventional insulin injections, to a trial of CSII in the hope that a period of prolonged metabolic near-normalisation might retard the progression of her retinopathy.

\section{Case report}

The patient was a 20-year-old girl with insulindependent diabetes for 15 years who had a single

Correspondence to Dr E. M. Kohner, Department of Medicine, Royal Postgraduate Medical School, Hammersmith Hospital, London W12 0HS. morning injection of protamine zinc insulin (PZI) 26 units and soluble insulin (SI) 32 units. She never performed home urine tests and only rarely had plasma glucose concentrations estimated. At the age of 7 years an accident blinded her right eye. Vision in her left eye had been previously good but had deteriorated in the months before admission. Retinopathy was noted in this her only functional eye, and she was referred for urgent management.

When first examined she had a visual acuity of $6 / 18$. Fundal abnormalities included multiple microaneurysms, large blot haemorrhages, and venous dilatation (Fig. 1a). Fluorescein angiography ${ }^{8}$ showed extensive microvascular changes, capillary dilatation, small areas of capillary nonperfusion, and on late pictures extensive leakage (Figs. 1b-d).

She was admitted to a metabolic ward for initial assessment and stabilisation. On the first day plasma glucose was measured (glucose oxidase method) 2-hourly for $\mathbf{2 4}$ hours on the conventional insulin regimens, and subsequently when she was stabilised on CSII (Table 1).

Highly purified porcine insulin (Actrapid, Novo Industries) was continuously infused through a fine nylon cannula (Portex Ltd, Hythe, Kent). Its distal end was implanted under the skin of the anterior abdominal wall, and the other end connected to a portable battery-driven syringe pump (Mill Hill infuser, Model 1001A, Muirhead Ltd, Beckenham, Kent) which had been adapted to deliver the insulin solution at two rates $(50 \mu \mathrm{l}$ and $400 \mu \mathrm{l} / \mathrm{hour})$. The high rate was activated by the patient 30 minutes 


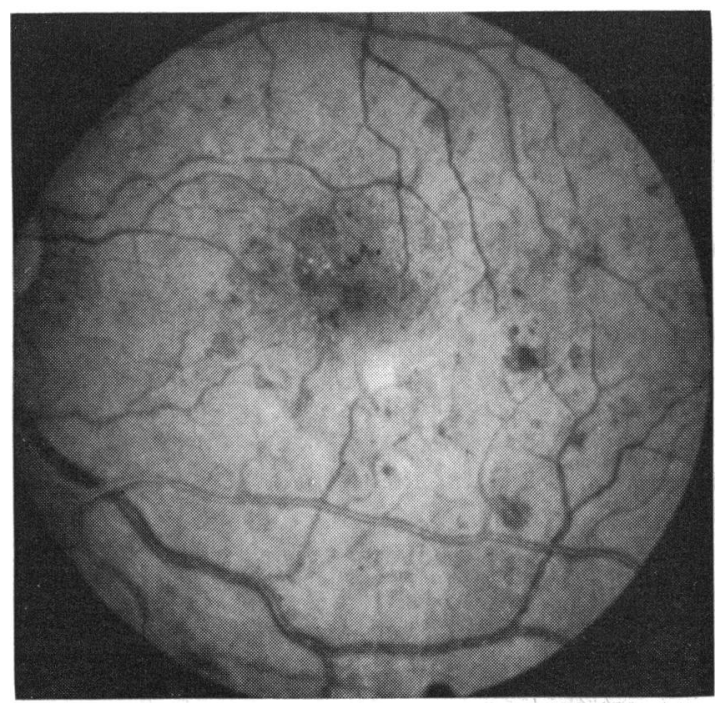

1a

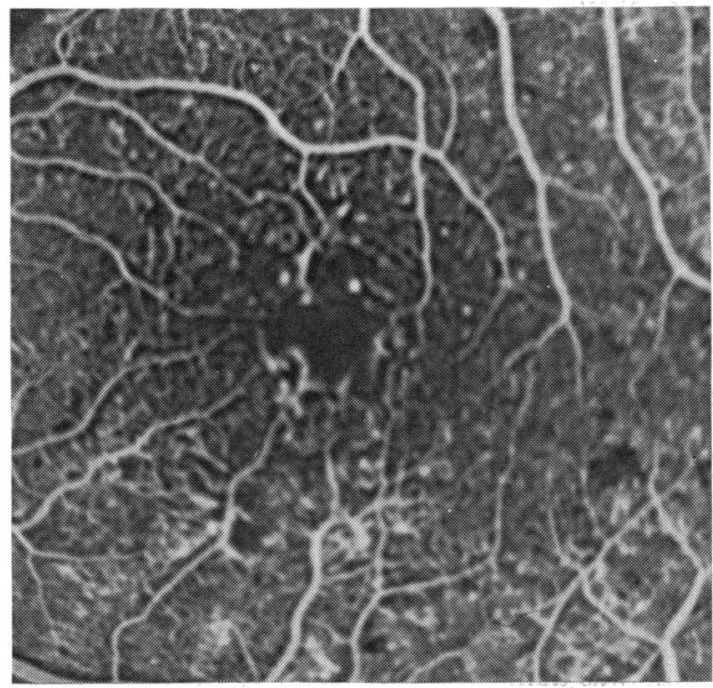

1c

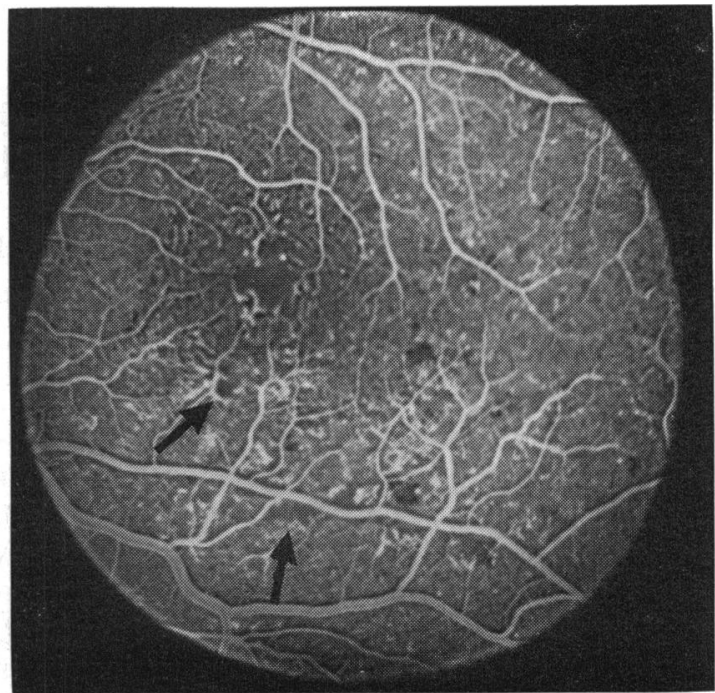

$1 \mathrm{~b}$

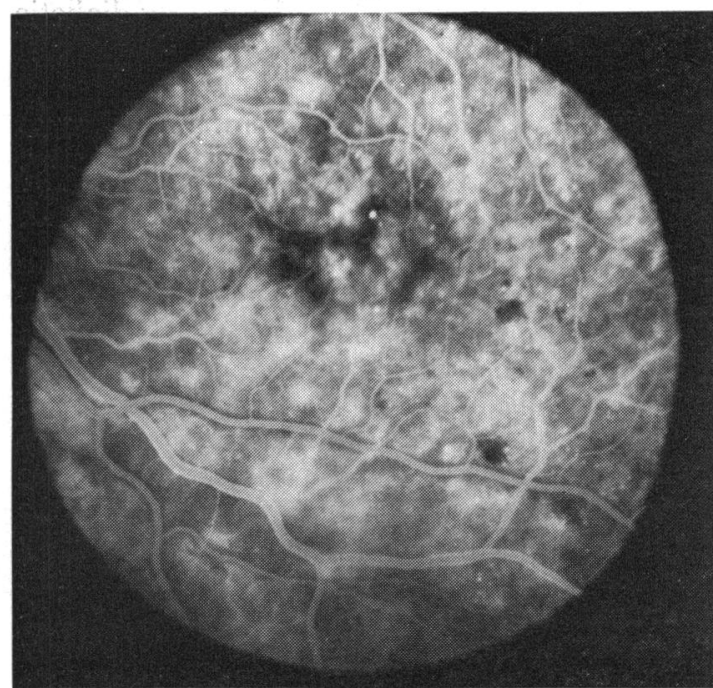

1d

Fig. 1 (a) Fundus photograph of left macula showing multiple blot haemorrhages, microaneurysms, and generalised venous dilatation. (b) Fluorescein angiogram in capiliary phase illustrates generalised capillary dilatation and areas of nonperfusion (arrowed). (c) Macular detail of Fig. 1 (b) showing more clearly areas of dilatation, capillary nonperfusion. and microaneurysms. (d) Fluorescein angiogram in the late venous phase illustrating extensive capillary leakage.

before main meals and automatically returned to the basal rate after 17 minutes. The pump was worn on a belt round the waist.

The patient was taught to estimate capillary blood glucose concentrations using glucose oxidase strips (Dextrostix, Ames and Miles), and did so at least 4 times a day while in hospital and at home. She also replaced and refilled her syringe daily with insulin (diluted as instructed with $0.154 \mathrm{mmol} / 1$ saline). After initial stabilisation on CSII in hospital the infusion was continued at home under very close and regular hospital supervision. Altogether she was maintained on CSII for 65 days, which was continuous except for 3 days when the cannula became accidentally dislodged from its subcutaneous site. Subsequently she has been controlled on a twicedaily regimen of Actrapid and Semitard (Novo Industries). 


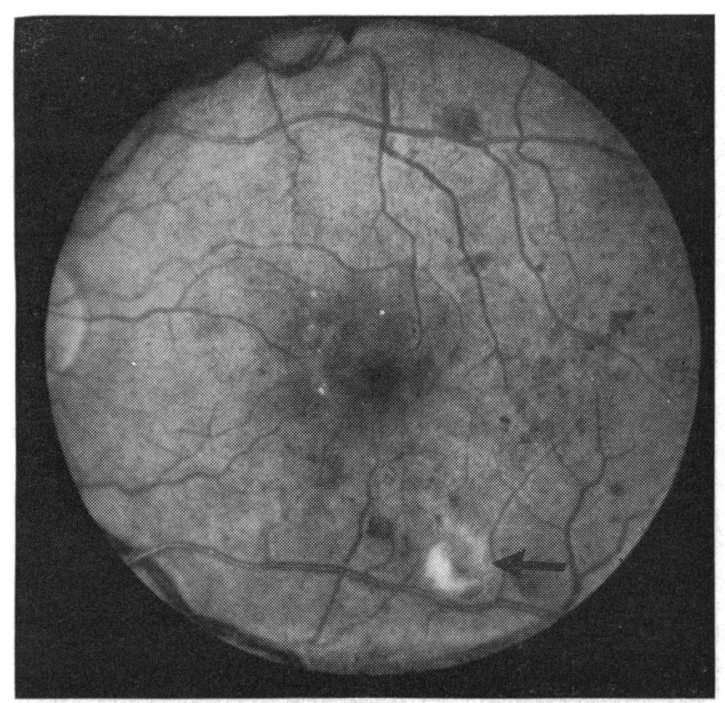

$2 a$

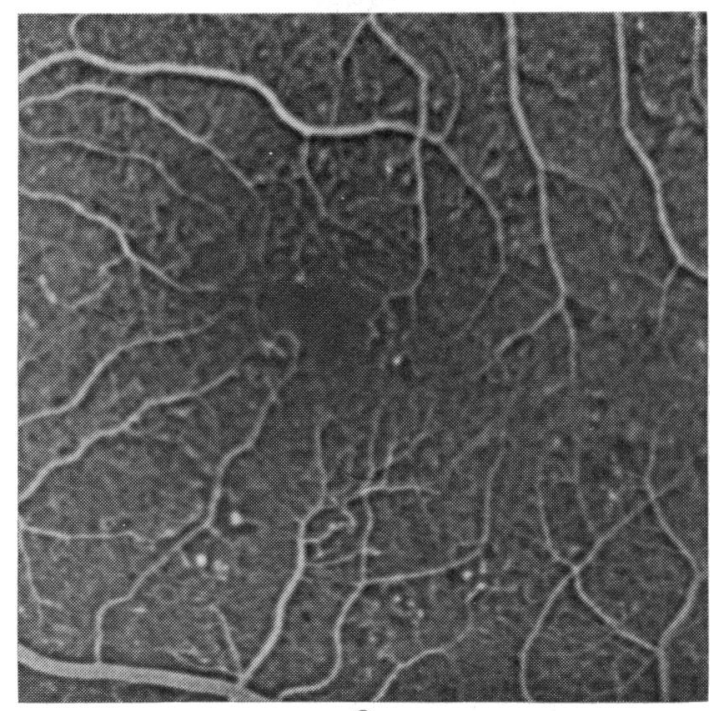

2c

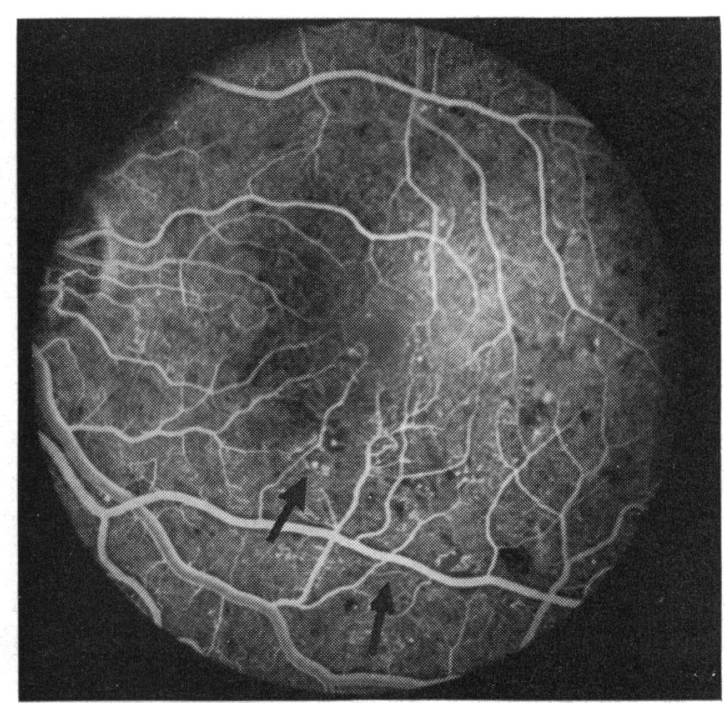

$2 b$

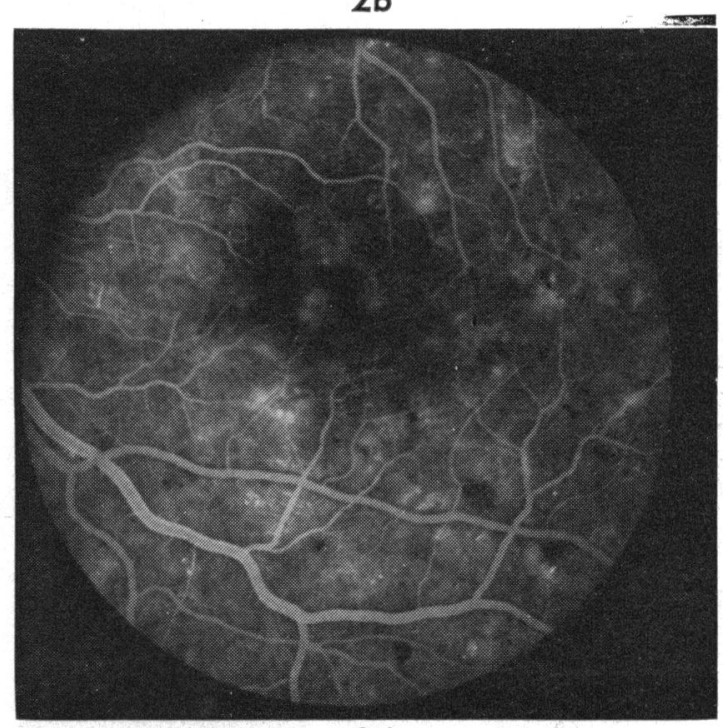

2d

Fig. 2 (a) Fundus photograph of left macula 65 days after starting CSII. Improvement in haemorrhages and less venous dilatation; but cotton-wool spot has developed (arrowed). (b) Fluorescein angiogram in same phase as Fig. 1 (b). Note reduction in capillary dilatation. Revascularisation of some areas of previous nonperfusion is now present (arrowed). (c) Enlarged detail of macular area shown in 2 (b). Marked reduction in capillary dilatation and improvement in areas of capillary nonperfusion. (d) Fluorescein angiogram in same phase as Fig. 1 (d). Marked reduction in capillary leakage present.

Continuous physiological levels of blood glucose ( $<9.7 \mathrm{mmol} / \mathrm{l}$ ) were not obtained on CSII for 28 days because of a technical problem with the pump, but thereafter were almost always normal. There was a highly significant reduction in plasma glucose levels $(p<0.01)$ after stabilisation on CSII from the levels on conventional therapy (Table 1). Mainten- ance of blood glucose concentrations within the physiological range has been achieved for most of the time while on the current regimen of twice-daily subcutaneous injections, though the results are not as good as on CSII alone (Table 1).

Repeat fundoscopic examinations 65 days after the initiation of CSII and only 36 days after con- 


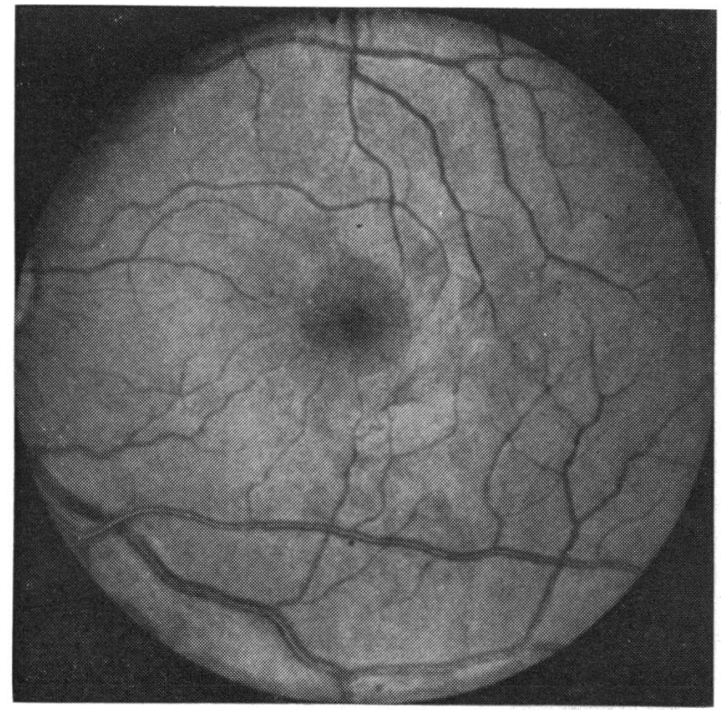

$3 a$

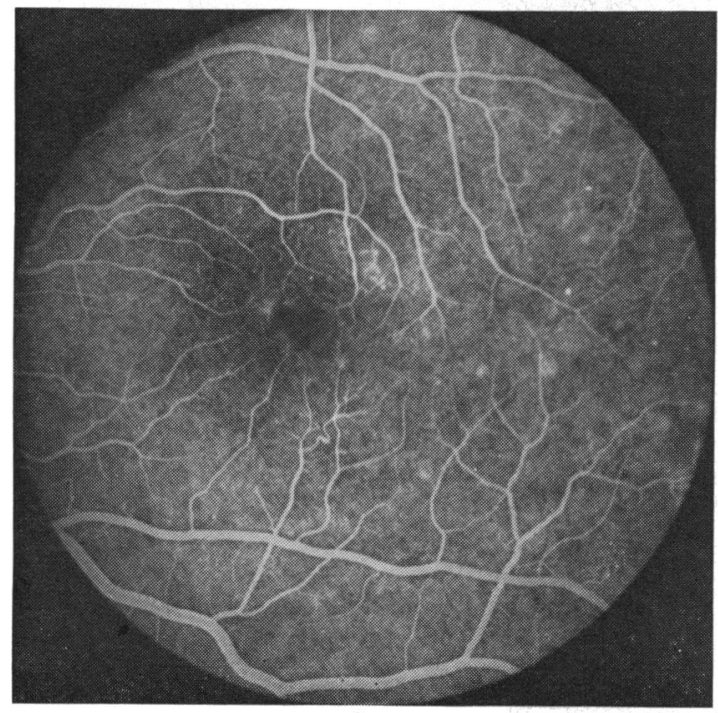

$3 c$

tinuous normoglycaemia had been established showed absorption of some of the haemorrhages and a reduction in the microaneurysms previously demonstrable, but a few cotton-wool spots had developed (Fig. 2a). Fluorescein angiography revealed a marked reversal of microvascular lesions and leakage (Figs 2b, c). There was normal revascularisation in some areas of previous nonperfusion and a reduction in capillary dilatation (Fig. 2d). Visual acuity had improved from $6 / 18$ to $6 / 6$ by the end of the period of CSII. Following the infusion the retinopathy showed signs of continued improvement

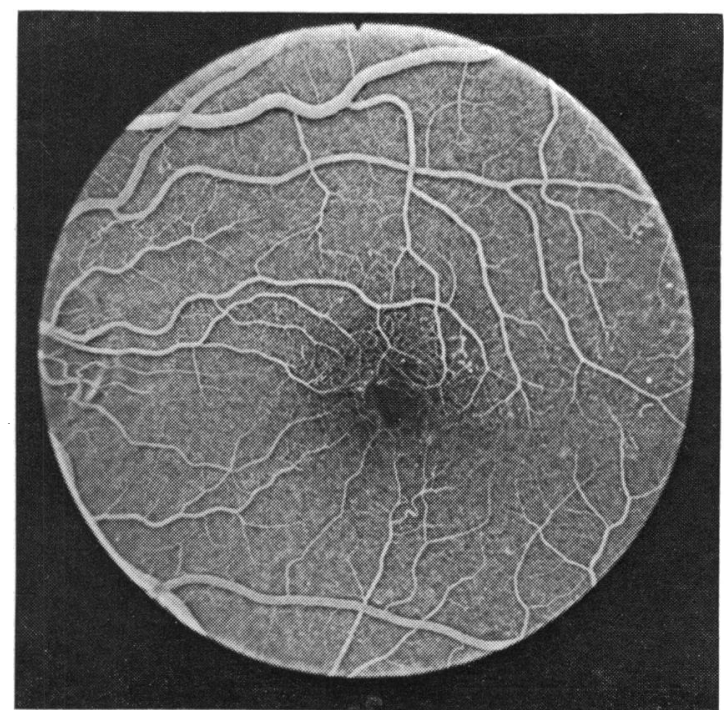

$3 b$

Fig. 3 (a) Fundus photograph of left macula 18 months after initiation of good diabetic control. Marked reduction in number of microaneurysms and haemorrhages. No cotton-wool spots present. (b) Fluorescein angiogram in capillary phase shows further improvement of capillary bed. (c) Fluorescein angiogram in the late venous phase showing continued improvement in leakage.

18 months later (Figs. 3a-c) with the patient well controlled on twice daily subcutaneous insulin injections.

\section{Discussion}

This case shows that some of the retinal microvascular complications of diabetes can be rapidly reversed when continuous near-normoglycaemia is achieved with CSII, and the improvements may continue when good diabetic control is established on a conventional subcutaneous insulin regimen. 
Table 1 Blood glucose levels before, during, and after CSII

\begin{tabular}{ll}
\hline & $\begin{array}{l}\text { Mean blood glucose } \\
\text { mmolll }( \pm S D)\end{array}$ \\
\hline $\begin{array}{c}\text { Once daily insulin prior to CSII } \\
\text { (2-hourly levels over 24 hours) }\end{array}$ & $11 \cdot 1 \pm 3 \cdot 6$ \\
$\begin{array}{l}\text { After initial stabilisation on CSII } \\
\text { (2-hourly levels over 24 hours) }\end{array}$ & $4 \cdot 9 \pm 2 \cdot 4$ \\
$\begin{array}{l}\text { Over 65 days on CSII } \\
\text { (4 estimations/day)* }\end{array}$ & $6 \cdot 1 \pm 2 \cdot 1$ \\
$\begin{array}{l}\text { Over 18 months on twice-daily insulin } \\
\text { after CSII (4 estimations/day) } \dagger\end{array}$ & $7 \cdot 6 \pm 2 \cdot 3$
\end{tabular}

-Estimated by Dextrostix. †Estimated by Dextrostix and home blood glucose monitor.

Previous studies in man assessing the relationship between diabetic control and retinopathy have been inconclusive, largely because of the practical difficulties in obtaining comparable groups of diabetics who are assigned to different levels of metabolic control over adequate time periods. Nevertheless several authors have inferred that poor metabolic control is important in the development of retinopathy. ${ }^{9-11}$ Others, however, have argued that good control has no influence on established diabetic retinopathy ${ }^{12}{ }^{13}$. In man the evidence is still anecdotal, and such a criticism could be levelled at the case here, particularly as unexplained, apparently spontaneous remission of retinopathy may occur. ${ }^{14}$ However, the degree and the rapidity of reversal of retinopathic changes in our patient using CSII to induce continuous normoglycaemia must be very unusual.

We have never observed such changes over such a short time interval, though similar results have been described in some patients 3 months after treatment by pituitary ablation with yttrium-90.15

Other methods of achieving equally good blood glucose control may be as successful as CSII, but the latter has the advantage of delivering insulin in a more physiological manner than conventional methods, and this may be of critical importance in achieving the observed effects as in this case. Once established it appears that the improvement can be maintained on a conventional insulin regimen.

While conclusions cannot be drawn from a single case, we suggest that a therapeutic trial of normalisa- tion of blood sugar with CSII in early and preproliferative retinopathy may be indicated.

This work was supported by the British Diabetic Association.

References

1 Engerman R, Bloodworth JMB, Nelson S. Relationship of microvascular disease in diabetes to metabolic control. Diabetes 1977; 26: 760-9.

2 Pickup JC, Keen H, Parsons JA, Alberti KGMM. Continuous subcutaneous insulin infusion: an approach to achieving normoglycaemia. $\mathrm{Br}$ Med J 1978; i: 204-7.

3 Pickup JC, Keen H, Parsons JA, Alberti KGMM. Continuous subcutaneous insulin infusion. Good blood glucose control for up to 4 days. Diabetologia 1979; 16: 385-9.

4 Pickup JC, White MC, Keen H, Kohner EM, Parsons JA, Alberti KGMM. Long term continuous subcutaneous insulin infusion in diabetics at home. Lancet 1979; ii: $870-3$.

5 Pickup JC, Keen H, Parsons JA, Alberti KGMM Continuous subcutaneous insulin infusion: prolongation of control and correction of intermediary metabolites. Diabetologia 1978; 14: 261 (abstract).

6 Tamborlane WV, Sherwin RS, Renel M, Felig P. Restoration of normal lipids and amino acid metabolism in diabetic patients with a portable insulin infusion pump. Lancet 1979; i: 1258-62.

7 Kohner EM, Hamilton AM, Joplin GF, Fraser TR. Florid diabetic retinopathy and its response to treatment by photocoagulation or pituitary ablation. Diabetes 1976; 25: 104-10.

8 Kohner EM, Dollery CT, Paterson JW, Oakley NW. Arterial fluorescein studies in diabetic retinopathy. Diabetes 1967; 16: 1-10.

9 Kohner EM, Fraser TR, Joplin GF, Oakley NW. The effect of diabetic control on diabetic retinopathy. In: Goldberg MF, Fine SL, eds. The Treatment of Diabetic Retinopathy. Washington: US Public Health Service Publication No. 1890, 1969; 119-28.

10 Miki E, Fukuda M, Kuzuya T, Kosaka K, Nakao K. Relation of the course of retinopathy to control of diabetes, age, and therapeutic agents in diabetic Japanese patients. Diabetes 1969; 18: 773-80.

11 Job D, Eschwege E, Guyot-Argenton C, Aubry JP, Tchobroutsky G. Effect of multiple daily insulin injections on the course or diabetic retinopathy. Diabetes 1976; 25: 463-9.

12 Schlesinger FG, Franken S, Van Lange LTP, Schwartz F. Incidence and progression of retinal and vascular lesions in long term diabetes. Acta Med Scand 1960; 168: 483-8.

13 Burditt AF, Caird FI, Draper GJ. The natural history of diabetic retinopathy. $Q J$ Med 1968; 37: 303-17.

14 Gerritzen FM. The course of diabetic retinopathy. A longitudinal study. Diabetes $1973 ; 22: 122-8$.

15 Kohner EM, Dollery CT, Fraser TR, Bulpitt CJ. The effect of pituitary ablation on diabetic retinopathy studied by fluorescein angiography. Diabetes 1970; 18: 703-14. 